\title{
ESPÉCIES VEGETAIS PRESENTES EM PRAÇAS E AVENIDAS DO MUNICÍPIO DE ALDEIAS ALTAS, MARANHÃO, BRASIL
}

\author{
VEGETAL SPECIES PRESENT IN SQUARES AND AVENUES OF THE \\ MUNICIPALITY OF ALDEAS ALTAS, MARANHÃO, BRAZIL
}

\author{
Miguel Sena de Oliveira ${ }^{1}$, Alessandro Wagner Coelho Ferreira², Julyana Roberta Sena Lopes ${ }^{3}$, \\ Joyce Ribeiro dos Reis ${ }^{4}$, Wagner Ribeiro da Silva Junior ${ }^{5}$, Jackson Amaral Costa ${ }^{6}$
}

\section{RESUMO}

A vegetação é fundamental e indispensável para as cidades, pelos inúmeros benefícios que as mesmas oferecem, melhorando a qualidade de vida das populações dos centros urbanos. Objetivo desse estudo é apresentar um inventário das espécies vegetais presentes em praças e avenidas do município de Aldeias Altas - MA. Os dados foram obtidos através de visitas ao município entre os meses de janeiro a maio de 2017. Foram percorridas as praças e avenidas realizando um inventário dos espécimes vegetais que compõe a paisagem desses espaços públicos. Foram listados 353 indivíduos de 25 espécies, distribuídas em 13 famílias botânicas, sendo Arecaceae (4 espécies, 31\%), Fabaceae (4 espécies, 31\%) e Apocynaceae (3 espécies, $23 \%$ ) as famílias mais representativas. Constatou-se que $(60 \%)$ das espécies encontradas eram arbóreas, e que $80 \%$ são de origem exótica. A espécie Azadirachta indica (nim) com (62\%) foi a mais frequente. Com base nesses dados constatou-se a necessidade da criação de um plano diretor de arborização urbana, que vise aumentar a introdução de espécies nativas, a fim de aproveitar mais a riqueza florística do Brasil e evitar a homogeneidade desses locais, tornando-os cada vez mais agradáveis a população e ecologicamente contextualizados.

Palavras-chave: Arborização urbana; Paisagismo; Plantas exóticas.

\begin{abstract}
Vegetation is fundamental and indispensable for the cities, for the innumerable benefits that they offer, improving the quality of life of the urban centers' populations. This study aims to present an inventory of the plant species present in squares and avenues of the municipality of Aldeias Altas - MA. Data were obtained through visits to the municipality between the months of January and May of 2017. An inventory of squares and avenues were carried, listing the vegetal specimens that compose the landscape of these public spaces. A total of 353 individuals of 25 species were found, distributed in 13 botanical families, being Arecaceae (4 species, 31\%), Fabaceae (4 species, 31\%) and Apocynaceae ( 3 species, 23\%) the most representative ones. It was found that $60 \%$ of the species are arboreal, and $80 \%$ are of exotic origin. The species Azadirachta indica (nim), with $62 \%$, was the most frequent species. Based on these data, it is necessary to create a master plan for urban afforestation, aiming to increasing the introduction of native species, in order to take advantage of Brazil's floristic richness and to avoid the homogeneity of these sites, making them increasingly more pleasing to the population and ecologically contextualized.
\end{abstract}

Keywords: Urban afforestation; Landscaping; Exotic plants.

Recebido em 27.07.2017 e aceito em 17.11.2017

1 Graduado em Ciências Biológicas-Licenciatura, Universidade Estadual do Maranhão (UEMA), Caxias, Maranhão. Email: miguelsena2010@hotmail.com

2 Biólogo, Dr., Professor da Universidade Federal do Maranhão(UFMA), São Luis, Maranhão. Email: alessandrowcf@yahoo.com.br

3 Graduanda em Ciências Biológicas-Licenciatura, UEMA, Caxias, Maranhão. Email: julyanaroberta9@gmail.com

4 Graduanda em Ciências Biológicas-Licenciatura, Instituto Federal de Educação, Ciência e Tecnologia do Maranhão- IFMA, Caxias, Maranhão. Email: joycereis878@gmail.com

5 Graduando em Ciências Biológicas-Licenciatura, UFMA, São Luis, Maranhão Email: wagner.botany@gmail.com

6 Graduado em Geografia-Licenciatura, UEMA, Caxias, Maranhão. Email: jacksoncosta22cx@gmail.com 


\section{INTRODUÇÃO}

Inseridos nos centros urbanos, a vegetação, pelos vários benefícios que podem proporcionar ao meio urbano, tem um papel muito importante no restabelecimento da relação entre o homem e o meio natural à medida que proporcionam a sensação de bem estar psicológico; melhorando a qualidade do ar; amortecendo o som, amenizando a poluição sonora; oferecendo sombra para os pedestres e veículos; reduzindo o impacto da água das chuvas e seu escorrimento superficial; preservando a fauna silvestre e refrescando o ambiente pela grande quantidade de água transpirada pelas folhas. (PIVETTA; SILVA FILHO, 2002).

De ponto de vista ecológico e paisagístico, uma cidade bem arborizada contribui não só com aspectos estéticos, mas também com a qualidade de vida, à medida que promovem o bem estar social através do lazer e recreação que proporcionam a população dos centros urbanos. Pois, espaços públicos como praças, tem a função de proporcionarem convivência sadia à população, além de buscar a democratização do acesso ao esporte e ao lazer, incentivar a inclusão social e a expressão cultural, além dos benefícios psicológicos (antiestresse), fisiológicos, econômicos (agregando valor às propriedades) e sociais (DANTAS; GOMES; PINHEIRO, 2016).

A arborização em vias públicas é fundamental e indispensável para o desenvolvimento urbano. Contudo, quando não há o planejamento adequado, inúmeros problemas podem ocorrer, e ao invés de um elemento benéfico, a arborização passa a representar um foco de conflito nas cidades (COLETTO; MÜLLER; WOLSKI, 2008).

Em um projeto sustentável de uma cidade, a arborização traz inúmeros benefícios como absorção do carbono emitido pelos veículos e demais atividades humanas na cidade; Diminuir a temperatura ("ilhas de calor") através da sombra e transpiração de vapor pelas árvores; Filtragem e remoção de gases e partículas poluentes do ar; Atenuação da poluição sonora urbana; Favorecimento de maior equilíbrio ambiental através da manutenção da biodiversidade de animais (CEMIG, 2011). Entretanto, parte desses benefícios são reduzidos quando falta o planejamento na implantação e manutenção da arborização urbana. $O$ problema é maior quando há a utilização de espécies exóticas e a falta de área livre de pavimento para o desenvolvimento arbóreo (EMER et al., 2014).

As áreas verdes são fundamentais para a vida urbana, por isso, alguns cuidados são necessários para evirar desequilíbrios ecológicos relacionados, principalmente a perda da diversidade e com a homogeneização. Pois, a predominância de poucas espécies na arborização de uma cidade traz sérias consequências para o ecossistema urbano, como o aumento de gases poluentes na atmosfera, alterações no microclima, redução e evasão da fauna, assim como o ataques de pragas e doenças, haja vista que a diversidade da vegetação 
é de suma importância para a ampliação e fixação da fauna, e para a manutenção do equilíbrio biológico e o controle de pragas (DAMO; HEFLER; JACOBI, 2015).

Estudos voltados a conhecer as espécies vegetais utilizadas no paisagismo urbano, em locais como praças e avenidas, contribuem diretamente com informações que auxiliam a administração pública a gerir, planejar e a preservar esses espaços, fazendo com que a mesma atenda a aspectos ecológicos e estéticos na escolha e introdução das espécies nas cidades. No Maranhão, estudos desse tipo são escassos, podendo ser citados os trabalhos de Moraes e Machado (2014), Barbosa, Lopes e Lopes (2015) e Costa et al. (2017). Nesse sentido, este estudo teve como objetivo realizar um inventário das espécies vegetais presentes nas praças e canteiros centrais das avenidas do município de Aldeias Altas - MA. Com o intuito de caracterizar as espécies que atualmente que compõem a florística urbana e apresentar informações que contribuam com melhorias ao planejamento, paisagismo e arborização do município.

\section{MATERIAL E MÉTODOS}

\section{Área de estudo}

O município de Aldeias Altas (Figura 1) está localizado na Região Leste Maranhense, na Microrregião de Coelho Neto, entre as coordenadas 451'32" S e 4321'2" O, a 94 metros de altitude. O clima é tropical quente e subúmido, com dois períodos bem definidos: um chuvoso, de janeiro a junho e outro seco, de julho a dezembro. A temperatura média anual é de cerca de $27^{\circ} \mathrm{C}$. A vegetação do município apresenta características de Cerrado entremeado de Babaçual e Floresta Secundária, fruto de intensa fragmentação florestal devido práticas agropecuárias. Possui uma área territorial de $1.942,114 \mathrm{Km}^{2}$ e sua população atualmente estimada em 26.115 habitantes (OLIVEIRA et al., 2016; ALDEIAS ALTAS, 2011).

Foram estudadas todas as praças e avenidas do Município de Aldeias Altas - MA (Figura 1), foram elas, as praças Gonçalves Dias, Magno Bacelar e Vila Costa Pinto e as avenidas João Machado Araújo Rosa com (ca. 989 metros) e Alderico Machado (ca. 1.246 metros). 


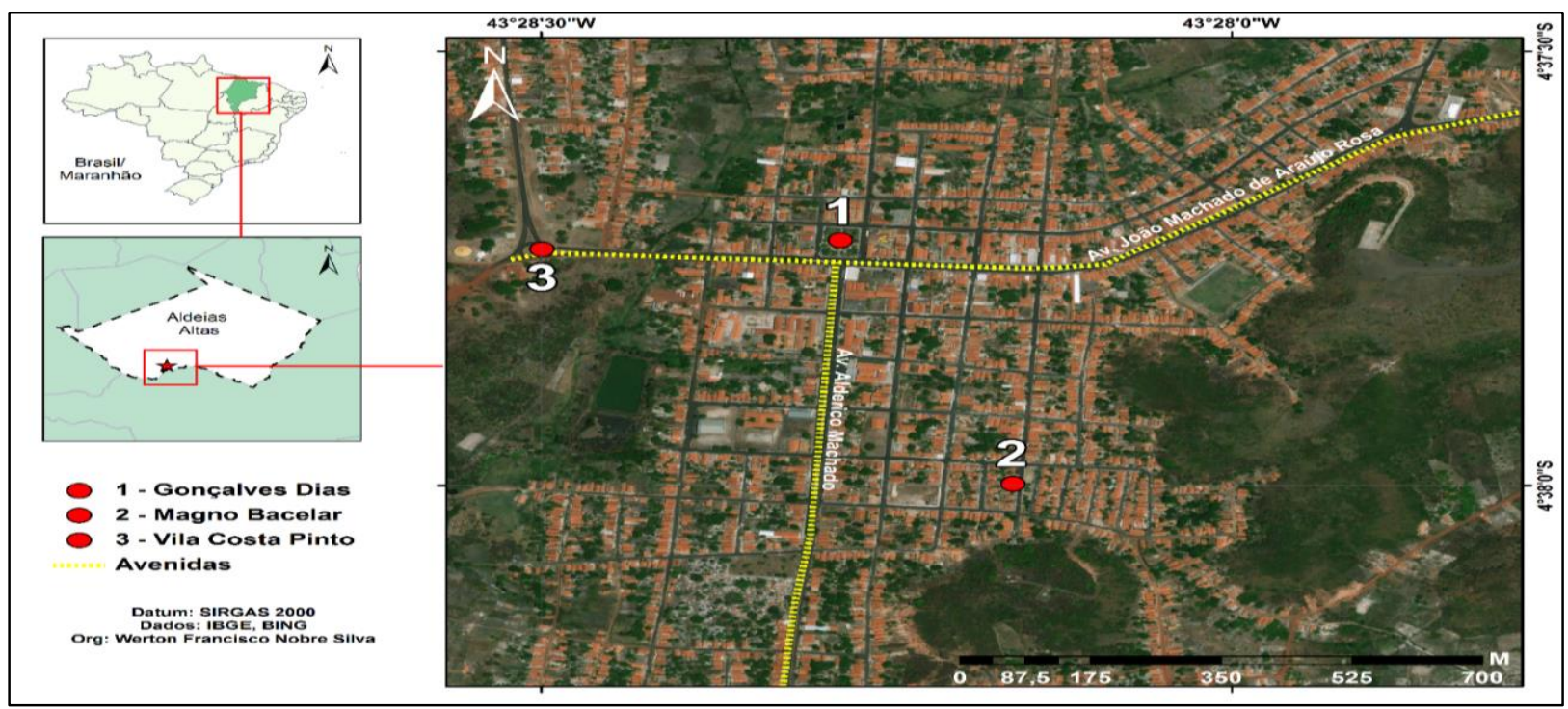

Fonte: IBGE, 2006; Organização: SILVA, W.F.N.2017

Figura 1. Vista aérea de parte do município de Aldeias Altas (MA), evidenciando os locais estudados Figure 1. Aerial view of the municipality of Aldeias Altas (MA), evidencing the sites studied

\section{Coleta de dados}

Os dados foram obtidos através de visitas mensais ao município entre os meses de janeiro a maio de 2017. Foram percorridas as praças e avenidas realizando um inventario dos espécimes vegetais que compunham a paisagem desses espaços públicos.

Quando se tratava de espécies conhecidas, as mesmas tiveram sua identificação in loco pelos taxonomistas da equipe. Quando não, tiveram suas identidades taxonômicas confirmadas com o uso de chaves dicotômicas e de literatura especifica (BEZERRA; CASTRO; BOTREL, 2017; COSTA et al., 2017; MORAES; MACHADO, 2014). E por comparação com exsicatas disponíveis no Herbário virtual SpeciesLink (2017).

O sistema de classificação botânica utilizado foi o APG IV (2016), e para grafia correta dos nomes científicos, assim como a determinação de suas origens (nativa ou exótica), foi utilizado a base de dados da Lista da Flora do Brasil (2017). Sendo que as espécies classificadas como naturalizadas, neste estudo, foram consideradas exóticas.

A frequência relativa das espécies, foi obtida pela divisão entre o número de indivíduos da espécie pelo número total de indivíduos, multiplicados por 100, assim como Camaño et al. (2015).

Para se quantificar a diversidade florística deste inventário, foi utilizado o índice de Shanon-Wiener, gerado pelo Software DivEs - Diversidade de Espécies v4.0.0.582. 


\section{RESULTADOS E DISCUSSÃO}

Neste estudo, foram listados 353 indivíduos de 25 espécies, distribuídas em 13 famílias botânicas e 24 gêneros (Tabela 1). As famílias com maior riqueza foram Arecaceae (4 espécies, 31\%) e Fabaceae (4 espécies, 31\%), seguida por Apocynaceae (3 espécies, 23\%). Em um estudo com as espécies vegetais utilizadas na arborização de canteiros e praças em Tuparetama-PE, essas mesmas famílias também foram citadas por apresentarem a maior quantidade espécies (SILVA; RODRIGUES; LUCENA, 2017).

Tabela 1. Lista das espécies presentes nas praças e avenidas do município de Aldeias Altas-MA

\begin{tabular}{|c|c|c|c|c|c|c|}
\hline Família & Nome Cientifico & Nome popular & Categoria & Org. & FA & $\begin{array}{l}\text { FR } \\
(\%)\end{array}$ \\
\hline \multirow{2}{*}{ Anacardiaceae } & Mangifera indica L. & Mangueira & Arbórea & $E$ & 7 & 1,98 \\
\hline & Spondias mombin L. & Cajá & Arbórea & $\mathrm{N}$ & 1 & 0,28 \\
\hline \multirow{3}{*}{ Apocynaceae } & Allamanda polyantha Müll.Arg. & Alamandra & Arbustiva & $\mathrm{N}$ & 3 & 0,84 \\
\hline & Plumeria rubra L. & Jasmim- manga & Arbórea & $\mathrm{E}$ & 1 & 0,28 \\
\hline & Calotropis procera (Aiton) W.T.Aiton & Bombardeira & Arbustiva & $E$ & 1 & 0,28 \\
\hline \multirow{4}{*}{ Arecaceae } & Copernicia prunifera (Mill.) H.E.Moore & Carnaúba & Arbórea & $\mathrm{N}$ & 8 & 2,26 \\
\hline & Roystonea oleracea (Jacq.) O.F. Cook & Palmeira Imperial & Arbórea & $\mathrm{E}$ & 11 & 3,11 \\
\hline & Chrysalidocarpus lutescens H. Wendl. & Palmeira de Jardim & Arbórea & $E$ & 7 & 1,98 \\
\hline & Phoenix roebelenii O'Brien & Palmeira Fenix & Arbórea & $E$ & 10 & 2,53 \\
\hline \multirow{2}{*}{ Asparagaceae } & Agave angustifolia Haw. & Agave do Caribe & Arbustiva & $E$ & 3 & 0,84 \\
\hline & Dracaena fragrans (L.) Ker Gawl. & Coqueiro-de-vênus & Arbustiva & $E$ & 1 & 0,28 \\
\hline Bignoniaceae & Handroanthus sp. & Ipê & Arbórea & $\mathrm{N}$ & 25 & 7,34 \\
\hline Cactaceae & Opuntia ficus-indica (L.) Mill. & Figueira da Índia & Arbustiva & $E$ & 5 & 1,41 \\
\hline Combretaceae & Terminalia catappa L. & Amêndoa & Arbórea & $E$ & 18 & 5,09 \\
\hline \multirow{4}{*}{ Fabaceae } & Tamarindus indica L. & Tamarindo & Arbórea & $E$ & 5 & 1,41 \\
\hline & Arachis repens Handro & Grama-amendoim & Herbácea & $\mathrm{N}$ & N.I & N.I \\
\hline & Caesalpinia pulcherrima (L.) Sw. & Flor-de-pavão & Arbórea & $E$ & 1 & 0,28 \\
\hline & Erythrina variegata $\mathrm{L}$. & Brasileirinho & Arbórea & $E$ & 1 & 0,28 \\
\hline Meliaceae & Azadirachta indica A. Juss. & Nim indiano & Arbórea & $E$ & 218 & 62,0 \\
\hline \multirow{2}{*}{ Myrtaceae } & Syzygium cumini (L.) Skeels & Azeitona & Arbórea & $E$ & 16 & 5,01 \\
\hline & Syzygium jambos (L.) Alston & Jambo & Arbórea & $\mathrm{E}$ & 1 & 0,28 \\
\hline Poaceae & Bambusa vulgaris Schrad. ex J.C.Wendl & Bambú & Gramínea & $E$ & 3 & 0,84 \\
\hline \multirow{2}{*}{ Rubiaceae } & Ixora chinensis Lam. & Ixora-vermelha & Arbustiva & $E$ & N.I & N.I \\
\hline & Mussaenda philippica A.Rich. & Mussaenda-Rosa & Arbustiva & $E$ & 3 & 0,84 \\
\hline Strelitziaceae & Ravenala madagascariensis Sonn. & Árvore do Viajante & Herbácea & $E$ & 2 & 0,56 \\
\hline
\end{tabular}

Table 1. List of species present in the squares and avenues of the municipality of Aldeias Altas-MA

Nota: Org. = Origem; FA = Frequência Absoluta; FR = Frequência Relativa (\%); N.I = Número Indeterminado.

Das espécies listadas, observou-se que 60\% eram arbóreas, 28\% arbustivas, $8 \%$ herbáceas e que 4\% são gramíneas. A predominância das espécies arbóreas foram também evidenciadas em outros trabalhos para o Nordeste, como os (75\%) em Remígio-PB (BATISTA 
et al., 2013), os (74\%) em Natal-RN (SILVA, 2016) e os (51\%) em São João dos Patos-MA (BARBOSA; LOPES; LOPES, 2015). A preferência pelo uso das árvores no meio urbano justifica-se pelos benefícios que as mesmas proporcionam ao ser humano, como o bem estar psicológico, a sombra que proporcionam para os pedestres e veículos, por auxiliarem na regulação térmica e a melhoria que promovem na qualidade do ar (CEMIG, 2011).

O índice de Shanon-Wiener geral deste estudo foi de 2,43, sendo superior ao de 1,13 encontrado por Silva e Almeida (2016) na composição florística das praças do bairro de Neópolis, Natal-RN e inferior ao de 3,34 encontrado por Maria, Biondi e Brobowski (2016) em um inventário nas vias públicas de Itanhaém-SP, sendo ainda afirmado pelos autores, que o índice acima de 3 é considerado como uma boa diversidade de espécies. Portanto, visto que este índice leva em consideração a riqueza e a uniformidade da distribuição das espécies, pode-se então, afirmar que o valor encontrado neste estudo, mesmo diante deste pequeno número de praças (três) e avenidas (duas) que Aldeias Altas dispõem, o município está próximo do índice ideal de diversidade florística.

No município de Aldeias Altas, constatou-se que $80 \%$ das espécies (20 espécies) vegetais presentes em praças e avenidas são exóticas, e que apenas $20 \%$ são nativas (5 espécies) (Figura 2). Esses resultados corroboram com outros estudos semelhantes pelo Brasil, que apontam uma maior utilização das espécies exóticas no paisagismo, sendo a ornamentação o principal motivo de uso dessas espécies (BASTOS et., 2016; HOPPEN et al., 2014; BATISTA et al., 2013).

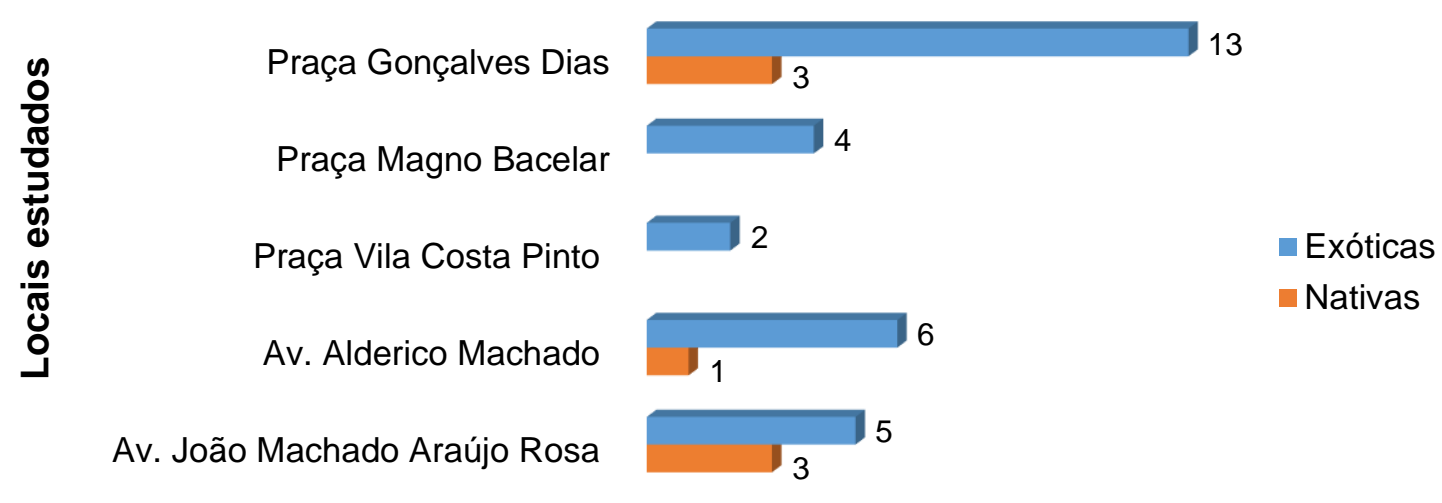

Frequência Absoluta (\%)

Figura 2. Origem das espécies presentes nas praças e avenidas do município de Aldeias Altas-MA

Figure 2. Origin of the species present in the squares and avenues of the municipality of Aldeias AltasMA

Entretanto, o ideal seria a substituição exóticas pelas nativas, tanto por aspectos regionais, na valorização da flora local, utilizando-as no embelezamento desses espaços, como ecológicos, pois as mesmas oferecem não só abrigo, como também alimento para a fauna da região, assim como sombra e lazer as ruas e avenidas das cidades (COLETTO; MÜLLER; 
WOLSKI, 2008). Segundo Biondi e Pedrosa-Macedo (2008) a vegetação introduzida nas cidades em áreas públicas como praças, parques, jardins de instituições públicas e arborização de ruas, dependem e têm grande influência da administração municipal.

Segundo Cecchetto, Christmann e Oliveira (2008), as espécies nativas possuem diversas vantagens em relação as exóticas, como a adaptabilidade garantida ao clima e solo; maiores possibilidades de produção de flores e frutos saudáveis; propicia a alimentação para animais também nativos, conservando a fauna local; promulga a proliferação da espécie, evitando a sua extinção; evita o aumento de espécies invasoras exóticas e as doenças e pragas ocasionadas pelas mesmas; além de oferecer os benefícios comuns a todos os gêneros arbóreos.

Azadirachta indica A. Juss. (nim) com 218 indivíduos dos 353 inventariados, foi a espécie mais numerosa com (62\%). Essa espécie de origem Asiática tem sido amplamente utilizadas pelas prefeituras na arborização de praças e avenidas, assim como pela população nas faixadas das residências. Sua presença tem sido frequentemente observada também em outras cidades do Maranhão como em Timon (MORAES; MACHADO, 2014), Caxias (COSTA et al., 2017) e São João dos Patos (BARBOSA; LOPES; LOPES, 2015).

O uso de $A$. indica na arborização tornou-se popular para Nordeste do Brasil, devido às características de rápido crescimento, potencial de sombreamento e resistência a condições adversas de solo e ao clima, fizeram com o que essa espécie tenha se adaptado bem nessa região (BEZERRA; CASTRO; BOTREL, 2017; SILVA; RODRIGUES; LUCENA, 2017).

No inventário, a espécie $A$. indica foi a mais frequente (62\%), sendo observada em todos os locais estudados, compondo principalmente a arborização das avenidas. Na Av. Machado Araújo Rosa, por exemplo, foram listados 196 indivíduos desta espécie, o que representa $86,7 \%$ de todas as espécies presentes na avenida, sendo que esse elevado percentual está em desacordo com os critérios de diversidade estabelecidos no manual de arborização Cemig (2011) que recomenda que não se ultrapasse os limites de $30 \%$ da mesma família, $20 \%$ do mesmo gênero e $10 \%$ de uma única espécie.

Dos locais estudados, a praça Gonçalves Dias, principal praça da cidade, foi a que apresentou a maior riqueza (Figura 3). Entretanto, das 16 espécies encontradas, apenas três são nativas. Esses resultados evidenciam a distribuição desproporcional das espécies, e a introdução maciça de espécies exóticas, assim como a baixa diversidade do uso da Flora nativa utilizadas nesse local.

As praças Magno Bacelar e Vila Costa Pinto, são compostas apenas por seis espécies (Figura 3), sendo todas de origem exótica. Esse resultado implica em riscos para a diversidade da florística desses locais, pois essa composição exclusiva de espécies exóticas demonstra a necessidade de uma maior inserção das espécies nativas, pois estás, são importantíssimas 
para o equilíbrio dos ecossistemas locais, sobretudo as que úteis para a fauna. Pois, quanto maior for a diversidade, menor serão os riscos da evasão da fauna, assim como as preocupações com a diminuição das comunidades vegetais urbanas ocasionados pelo ataque de pragas ou doenças.

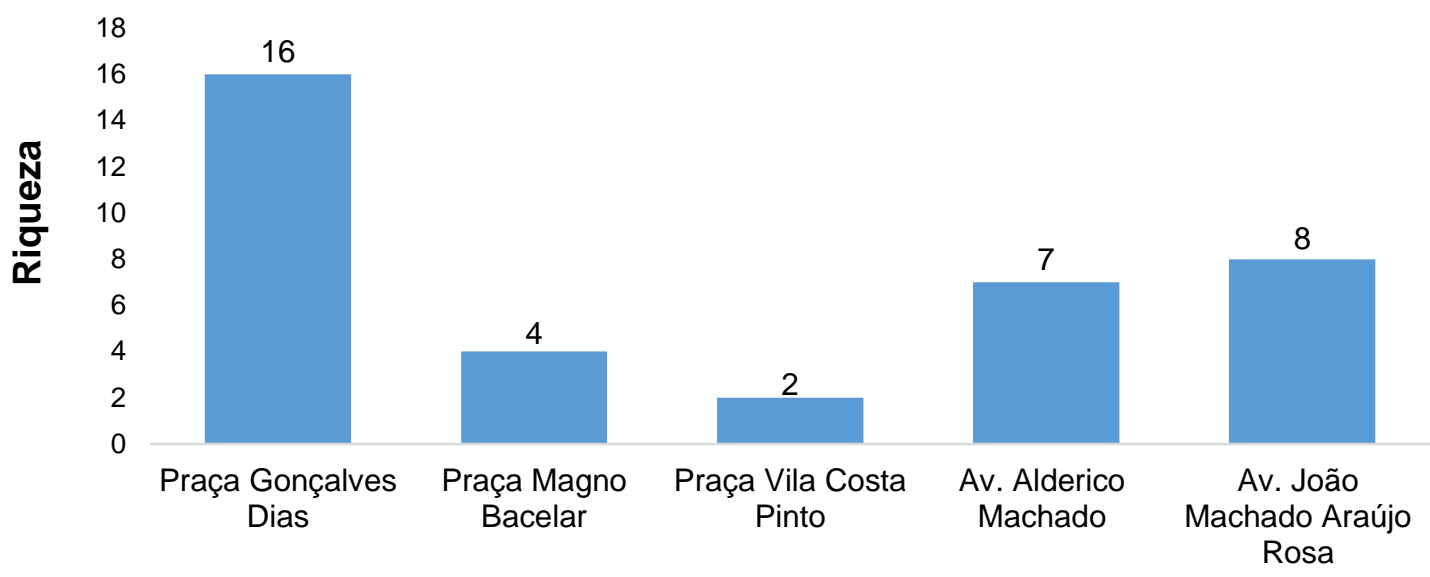

Figura 3. Riqueza das espécies presentes nas praças e avenidas do município de Aldeias Altas-MA

Figure 3. Richness of the species present in the squares and avenues of the municipality of Aldeias AltasMA

As espécies Ixora chinensis Lam. (Ixora-vermelha) e Arachis repens Handro (Gramaamendoim), ambas presentes na praça Gonçalves Dias (centro da cidade) não puderam ter seu número de indivíduos e frequências determinadas, pois as mesmas apresentaram-se respectivamente em formas de cercas-vivas plantadas em grupos irregulares e renques, ou em forma de gramando reptante, o que inviabilizou a quantificação dos indivíduos.

\section{CONCLUSÃO}

Neste inventário realizado no município de Aldeias Altas-MA, constatou-se que $80 \%$ das espécies utilizadas no paisagismo são de origem exótica, refletindo negativamente na diversidade da flora do município, demonstrando a necessidade da criação de um plano diretor de arborização urbana, que vise um aumento da introdução de espécies nativas com potencial ideal para a arborização urbana como Handroanthus serratifolius (Vahl) S.Grose (Ipê Amarelo); Handroanthus impetiginosus (Mart. ex DC.) Mattos (Ipê Roxo); Handroanthus heptaphyllus (Vell.) Mattos (Ipê Rosa); Clitoria fairchildiana R.A.Howard (Sombreiro); Senna spectabilis (DC.) H.S.Irwin \& Barneby (Cássia) dentre outras que proporcionam sombra, benefícios para a fauna e o embelezamento para as cidades. Também que atenda os índices dos $10 \%$ permitidos, a fim de evitar a homogeneidade desses locais, tornando-os cada vez mais agradáveis para a população e ecologicamente contextualizados. 


\section{REFERÊNCIAS}

ALDEIAS ALTAS. Relatório Diagnóstico do Município de Aldeias Altas. Disponível em: <http://rigeo.cprm.gov.br/xmlui/bitstream/handle/doc/15324/relaldeias_altas.pdf?sequence=1> Acesso em: 29 mar. 2017.

APG IV. An update of the Angiosperm Phylogeny Group classification for the orders and families of flowering plants: APG IV. Botanical Journal of the Linnean Society, Oxford, v. 181, n.1, p. 1-20, 2016.

BARBOSA, L. A.; LOPES, C. G. R.; LOPES, W. G. R. Levantamento das espécies vegetais das praças de São João dos Patos - MA. Revista da Sociedade Brasileira de Arborização Urbana, Piracicaba, v. 10, n. 1, p. 19-29, 2015.

BIONDI, D.; PEDROSA-MACEDO, J. H. Plantas invasoras encontradas na área urbana de Curitiba (PR). Floresta, Curitiba, v. 38, n. 1, p. 129-144, 2008.

BATISTA, F. A.; CHAVES, T. P.; FELISMINO, D. C.; DANTAS, I. C. Inventário quali-quantitativo da arborização urbana na cidade de Remígio, Paraíba. Revista de Biologia e Farmácia, Campina Grande, v. 9, n. 1, p. 70-83, 2013.

BEZERRA, M. B. S.; CASTRO V.; BOTREL, R. T. Arborização da avenida Jerônimo Rosado no município de Baraúna - RN, Brasil. Revista da Sociedade Brasileira de Arborização Urbana, Piracicaba, v. 12, n. 1, p. 122-131, 2017.

BAStOS, F. E. A.; CAMARGO, S. S.; MENEGUZZI, A.; KRETZSCHMAR, A. A.; RUFATO, L. Levantamento florístico e características das espécies em praças públicas em Lages-SC. Revista da Sociedade Brasileira de Arborização Urbana, Piracicaba, v. 11, n. 1, p. 34-42, 2016.

COSTA, C. F.; FONSECA, R. S.; ALMEIDA, D. B.; OLIVEIRA, M. S.; OLIVEIRA, D. S.; BRAGA, J. H. P. Espécies utilizadas na arborização em praças do município de Caxias, Maranhão. Revista da Sociedade Brasileira de Arborização Úrbana, Piracicaba, v. 12, n. 1, p. 65-78, 2017.

CAMAÑO, J. D. Z.; BARROSO, R. F.; SOUTO, P. C.; SOUTO, J. S. Levantamento e diversidade da arborização urbana de Santa Helena, no semiárido da Paraíba. Agropecuária Científica no Semiárido, Patos, v. 11, n. 4, p. 54-62, 2015.

CECCHETTO, C.T; CHRISTMANN, S.S; OLIVEIRA, T.D. Arborização urbana: importância e benefícios no planejamento ambiental das cidades. In: XVI Seminário Internacional de Educação no Mercosul, Cruz Alta - RS, 2015.

COMPANHIA ENERGÉTICA DE MINAS GERAIS (CEMIG). Manual de arborização. Belo Horizonte: Cemig, 2011. 112 p.

COLETTO, E. P.; MÜLLER, N. G.; WOLSKI, S. S. Diagnóstico da arborização das vias públicas do município de Sete de Setembro - RS. Revista da Sociedade Brasileira de Arborização Urbana, Piracicaba, v. 3, n. 2, p.110-122, 2008.

DANTAS, A.R.; GOMES, E.M.C.; PINHEIRO, A.P. Diagnóstico florístico da praça Floriano Peixoto na cidade de Macapá, Amapá. Revista da Sociedade Brasileira de Arborização Urbana, Piracicaba, v. 11, n. 4, p. 32-46, 2016. 
DAMO, A.; HEFLER, S. M.; JACOBI, U. S. Diagnóstico da arborização em vias públicas dos bairros cidade nova e centro na cidade de Rio Grande - RS. Revista da Sociedade Brasileira de Arborização Urbana, Piracicaba, v. 10, n. 1, p. 43-60, 2015.

EMER, A. A.; CADORIN, D. A.; SILVA, L.; MELLO, N. A. Arborização dos bairros Veneza e aeroporto em Pato Branco - PR. Revista da Sociedade Brasileira de Arborização Urbana, Piracicaba, v. 9, n. 2, p. 87-100, 2014.

HOPPEN, M. I.; DIVENSI, H. F.; RIBEIRO, R. F.; CAXAMBU, M. G. Espécies exóticas na arborização de vias públicas no município de Farol, PR, Brasil. Revista da Sociedade Brasileira de Arborização Urbana, Piracicaba, v. 9, n. 3, p. 173-186, 2014.

LISTA DA FLORA DO BRASIL. Jardim Botânico do Rio de Janeiro. Disponível em: <http://floradobrasil.jbrj.gov.br/> Acesso em: 29 mar. 2017.

MARIA, T. R. B. C.; BIONDI, D.; BROBOWSKI, R. Inventário florístico quali-quantitativo das vias púbicas de Itanhaém - SP. Revista da Sociedade Brasileira de Arborização Urbana, Piracicaba, v. 11, n. 4, p. 79-97, 2016.

MORAES, L. A.; MACHADO, R. R. B. Arborização urbana do município de Timon/MA: inventário, diversidade e diagnóstico quali-quantitativo. Revista da Sociedade Brasileira de Arborização Urbana, Piracicaba, v. 9, n. 4, p. 80-98, 2014.

OLIVEIRA, M. S.; SILVA, E. O.; FERREIRA, A. W. C.; GUARÇONI, E. A. E. Conhecimento e uso tradicional das espécies madeireiras e medicinais utilizadas no município de Aldeias Altas, Maranhão, Brasil. Enciclopédia Biosfera, Goiânia, v. 13, n. 24, p. 1160-1173, 2016.

PIVETTA, K. F. L.; SILVA FILHO, D. F. Boletim Acadêmico: Arborização Urbana. Jaboticabal: UNESP, 2002. $74 \mathrm{p}$.

SILVA, R. F. L.; RODRIGUES, J. S.; LUCENA, M. F. A. Avaliação das espécies vegetais utilizadas na arborização em canteiros e praças de Tuparetama, Pernambuco, Nordeste do Brasil. Revista da Sociedade Brasileira de Arborização Urbana, Piracicaba, v. 12, n. 1, p. 132-141, 2017.

SILVA, C. D. D.; ALMEIDA, L. M. Composição florística e fitossociológica das praças do bairro de Neópolis, Natal-RN. Revista Cultural e Científica do UNIFACEX, Capim Macio, v. 14, n. 2, p. 86-103, 2016.

SILVA, C. D. D. Composição florística do bairro Nossa Senhora de Nazaré, Natal-RN: Subsídios para arborização urbana. Unisanta Bioscience, Santos, v. 5, n. 2, p.169-175, 2016.

SPECIESLINK. Base de Dados Eletrônica. Disponível em: <http://http://splink.cria.org.br/> Acesso em: 29 mar. 2017. 